\title{
EXTENDED COMMUNICATION
}

\section{Adjunctive Behavior: AN UNDER-Reported Phenomenon in APPLIED BEHAVIOR ANALYSIS?}

An adjunctive or schedule-induced behavior may be generally defined as a behavior which is maintained indirectly by the typical controlling variables of another behavior, rather than directly by its own typical controlling variables. In prototype studies, animals have been found to display a variety of anomalous, excessive behaviors including eating, drinking, wheelrunning, airlicking, aggression, and escape. These "adjunctive" side effects are "induced" by exposure to certain contingent or noncontingent reinforcement schedules, or schedule parameters, originally intended to control such familiar target behaviors as key pecking and bar pressing.

The infrahuman studies suggest that a variety of human motor and autonomic behaviors may be subtle adjunctive side effects of variables controlling more obvious target behaviors. Potential candidates for human adjunctive behaviors range from (a) "normal" timefilling or "fidgety" patterns such as playing, idle conversing, finger-tapping, and beard-stroking, through (b) "neurotic" obsessive-compulsive or "nervoushabit" patterns such as nailbiting, snacking, and handwashing, to (c) "psychotic" patterns such as selfstimulating rituals, manic episodes, and rage outbursts. Potential candidates for human "inducing" schedules include home, office, classroom, and ward routines, whose time, effort, and consequence properties have long been suspected of side effects by lay and professional people.

Although many laboratory studies have been conducted on adjunctive behavior, few studies have been conducted explicitly on such behaviors within applied behavior analysis. For example, cumulative indexes of the Journal of the Experimental Analysis of Bebavior list 63 studies of adjunctive or schedule-induced aggression, escape, and polydipsia during the years 1958 through 1977 . In contrast, the cumulative index of the Journal of Applied Behavior Analysis does not even list the topics of adjunctive or schedule-induced behavior. $J A B A$ 's cumulative index does list 13 studies under the topics collateral behavior, collateral change, collateral effects, response class, response generalization, and side effects, five of which appear relevant to the analysis of adjunctive behavior in individuals. None of these five studies, however, explicitly mentions adjunctive or schedule-induced behavior, and to this writer's knowledge, neither of these technical terms have ever appeared in the text of $J A B A$.

Such mutual isolation of research areas is not a new problem (Krantz, 1971, 1972), and, in fact, specialization of this sort is regarded by some as a sign of a discipline's "maturity." In this case, however, it may have had undesirable effects on both research and application. Applied research on classroom behavior, for example, has not widely or explicitly discussed the possibly "adjunctive" relationship between on-task and off-task behavior. Nonetheless, some classroom outcomes reported thus far (Carnine, 1976; Marholin and Steinman, 1977) appear intriguingly similar to those reported in laboratory research on adjunctive behaviors. Thus, because of the mutual isolation of experimental and applied areas, applied behavior researchers have perhaps overlooked an empirical generalization potentially useful in the study of "symptom substitution" (Cahoon, 1968), side effects, response classes, and behavioral structure (Wahler, 1975).

Similarly, authors of "how-to" textbooks and workshcps on behavior modification have devoted little or no time to alerting consumers to the existence of adjunctive phenomena extrinsic to and intrinsic to treatment programs. As a result, this writer has observed numerous cases where professionals and paraprofessionals devoted strenuous, shortsighted, and futile efforts at directly modifying apparently adjunctive behaviors by imposing medications or consequences on them. In one such instance, a young retarded adult developed a bedwetting problem shortly after entering a sheltered workshop program. This problem occurred several times per week and persisted in spite of several reinforcement procedures applied to it and in spite of the fact that termination from the work placement was not contingent upon bedwetting. The problem ceased only when the client was terminated from the workshop because of poor work performance and enrolled in a day activity center. Absolutely no bedwetting was observed for several months until he began another workshop program, at which point bedwetting resumed. This problem has persisted in spite of renewed attempts at applying consequences to it, in spite of the fact that his work performance is entirely satisfactory and he expresses a desire to continue at the job, and in spite of the fact that there is still no contingent relation between bedwetting and termination of employment. In many such instances, it has proved more effective to modify the environmental "inducing" variables which originally produced the behaviors (Ayllon, Layman, and Kandel, 1975), in this case, some as-yet-undetermined time, effort, or consequence property of the work routine. Thus, ap- 
plied behavioral consumers have perhaps been deprived of an empirical generalization potentially useful in the development of non-simplistic, effective behavioral interventions.

For both substantive findings and bibliographies, interested readers may consult reviews by Falk (1971) and Staddon (1977) of infrahuman research as well as studies of human adjunctive behavior by Frederiksen and Peterson (1974) and Wallace, Sanson, and Singer (1978).

William S. Foster, University of Minnesota, Minneapolis, Minnesota 55455 .

\section{REFERENCES}

Ayllon, T., Layman, D., and Kandel, H. J. A behavioral-educational alternative to drug control of hyperactive children. Journal of Applied Behavior Analysis, 1975, 8, 137-146.

Cahoon, D. D. Symptom substitution and the behavior therapies: A reappraisal. Psychological Bulletin, 1968, 69, $149-156$.

Carnine, D. W. Effects of two teacher-presentation rates on off-task behavior, answering correctly, and participation. Journal of Applied Behavior Analysis, 1976, 9, 199-206.
Falk, J. L. The nature and determinants of adjunctive behavior. Physiology and Behavior, 1971, 6, 577-588.

Frederiksen, L. W. and Peterson, G. L. Schedule-induced aggression in nursery school children. Psychological Record, 1974, 24, 343-351.

Krantz, D. L. The separate worlds of operant and nonoperant psychology. Journal of Applied Behavior Analysis, 1971, 4, 61-70.

Krantz, D. L. Schools and systems: The mutual isolation of operant and non-operant psychology as a case study. Journal of the History of the Behavioral Sciences, 1972, 8, 86-102.

Marholin, D. and Steinman, W. M. Stimulus control in the classroom as a function of the behavior reinforced. Journal of Applied Behavior Analysis, 1977, 10, $465-478$.

Staddon, J. E. R. Schedule-induced behavior. In W. K. Honig and J. E. R. Staddon (Eds), Handbook of operant behavior. Englewood Cliffs, New Jersey: Prentice-Hall, 1977. Pp. 125-152.

Wahler, R. G. Some structural aspects of deviant child behavior. Journal of Applied Behavior Analysis, 1975, 8, 27-42.

Wallace, M., Sanson, A., and Singer, G. Adjunctive behavior in humans on a food delivery schedule. Pbysiology and Behavior, 1978, 20, 203-204.

Received 21 April 1978.

(Final Acceptance 17 August 1978.) 